\section{TELE-FELLOWSHIPS FOR ADDICTION MEDICINE}

To the editor:

The COVID-19 pandemic has been an eye-opener to the world. Global shutdown for infection control has moved workers to virtual workplaces for working remotely. Considering the infectious globalized world, the humbling experience of the COVID-19 pandemic may not wear off even after the pandemic is scientifically and officially over because the COVID-19 pandemic may have impressed and permanently imprinted upon the humanity that (a) human-to-human in-person interactions may be potentially contagious, always and (b) feasibility of virtual interfaces among humans may make humanto-human interactions safer, always. Therefore, without being skeptical about the new normal due to global reshaping of humanity, it may be time for Accreditation Council for Graduate Medical Education (ACGME) to consider tele-fellowships because freshly graduating residents or already practicing physicians may be better off not putting off their fulltime tele-medicine practicing jobs for getting mandatorily institutionalized education before being rewarded/awarded with degrees/certifications especially if the warranted clinical skills to practice new normal medical sub-specialties may be safely honed remotely.

Recently, US President Trump's June 26, 2020 executive order has infused fresh breath of air into the argument that skills may matter more than degrees. ${ }^{1}$ This may be especially true when online education-and-training may be breaking down the barriers and fortresses built and monopolized by classroom teaching-and-training traditions, ${ }^{2,3}$ which may obviously be very resistant to share their rights and privileges to satiate the inquisitive urges of the learners who have always been free to learn as long as they invest immense amounts of time and exorbitant amounts of money to learn whether traditionally in classrooms or futuristically online. These investments to acquire institutionalized termed/ tenured degrees/certifications are especially painful and sufferable when there are poorer returns on investment especially when the fast-changing world and its fast-changing needs warrant fast-changing adaptations by learning fast-changing skills. ${ }^{4-7}$
Essentially, if the COVID-19 pandemic is demonstrating that a majority of patient care can be safely delivered by remotely stationed caregivers, it is rightful to presume that astute populations and providers getting acclimatized to tele-medicine will be more than happy to embrace tele-training beginning with tele-fellowships as its first natural experiment into the future graduate medical education (GME). ${ }^{8}$ The GME fellowships in medical sub-specialties with inherent feasibility to safely deliver almost all patient care remotely may have more likelihood to be chosen as the test-subjects for this natural experiment and thus it seems apparent and appropriate to me that addiction medicine should be the chosen pioneer to tread this futuristic path. Firstly, as addiction medicine fellowships are being whole-heartedly embraced only lately due to the opioid epidemic in the United States, ${ }^{9}$ these fellowships can easily mold into tele-fellowships considering that they may not have yet developed longstanding traditions as difficult-to-shed baggage that interferes with fast-tracked adaptations for futuristic evolution. Secondly, as the opioid epidemic is far from over and may always need abundant supply of addiction medicine practicing physicians,${ }^{10}$ it is easier to fulfill societal healthcare needs by overcoming shortage of addiction medicine practitioners with tele-fellowships allowing fast-tracked training of freshly graduating residents or already practicing physicians who may not choose addiction medicine fellowships if they are not being trained remotely. Thirdly, as healthcare costs to society include not only what patients and their families bear in terms of insurance premiums and hospital charges but also what practitioners and their families bear in terms of time-periods invested and debts incurred,${ }^{11}$ it is safer to assume that freshly graduating residents or already practicing physicians will be better off when completing their tele-fellowships remotely without surrendering their fulltime tele-medicine jobs. Finally, when healthcare providers are already learning and readying to accept managing their patients remotely, repercussions of the COVID-19 pandemic are making a very strong case to move on to the next logical step where healthcare providers themselves are getting trained and skilled by futuristic virtuality to remotely manage their patients thus paving the futuristic path far away from traditional 
medicine/training (fellowships) and more towards tele-medicine/training (tele-fellowships).

Summarily, instead of burying our heads in the sand, the modern humanity must hold their heads even higher by farsightedly aiming to embrace the upcoming times of virtuality running the world. One of the futuristic ways demonstrating our astuteness will be to accept and promote healthcare training moving on to virtual platforms primarily even if not in totality, yet. This phasing out of traditional healthcare trainings may have to experimentally begin (and then permanently evolve) with phasing out of traditional GME fellowships paving the futuristic path for tele-fellowships at least for nascent medical sub-specialties like addiction medicine.

Deepak Gupta, MD Clinical Assistant Professor Department of Anesthesiology Wayne State University Detroit, Michigan

\section{REFERENCES}

1. The White House. Executive Order on Modernizing and Reforming the Assessment and Hiring of Federal Job Candidates. Available at: https://www.whitehouse.gov/presidential-actions/executive-order-modernizing-reforming-assessment-hiring-federal-job-candidates/ Accessed July 11, 2020.

2. York J: Teach Away. How teachers across the USA redefined the classroom during a pandemic. Available at: https:// www.teachaway.com/blog/redefining-class-online Accessed July 11, 2020.
3. Grad School Directory. Medical Specialties Online Graduate Programs. Available at: https://www.gradschools.com/programs/medical-specialties/online Accessed July 11, 2020.

4. Seltzer R: Inside Higher Ed. Return on Students' Investments Varies Over Time. Available at: https://www.insidehighered. $\mathrm{com} /$ news/2019/11/14/differences-college-roi-vary-institutiontype-and-time-frame-measured-report-says Accessed July 11, 2020.

5. Murakami K: Inside Higher Ed. Liberal Arts Pay Off in the Long Run. Available at: https://www.insidehighered.com/ news/2020/01/14/long-term-look-return-investment-revealspositive-indicators-liberal-arts Accessed July 11, 2020.

6. Rosenberg E: Investopedia. College Tuition vs. Investing: Is It Worth It? https://www.investopedia.com/articles/personalfinance/062515/college-tuition-vs-investing-it-worth-it.asp Accessed July 11, 2020.

7. Harari YN: What kids need from education in the 21st century. YouTube. Available at: https://www.youtube.com/watch $? v=0 \_u S p H M b O p E$ Accessed July 11, 2020.

8. American College of Telemedicine: Fellowships. Available at: http://www.acotm.org/fellowships/Accessed July 11, 2020.

9. Stone W: Aspiring doctors seek advanced training in addiction medicine. Los Angeles Times. March 27, 2019. Available at: https://www.latimes.com/nation/la-na-doctors-training-addictionmedicine-20190327-story.html Accessed July 11, 2020.

10. Vesta C: How Severe is the Shortage of Substance Abuse Specialists? The PEW Charitable Trusts. April 1, 2015. Available at: https://www.pewtrusts.org/en/research-and-analysis/blogs/ stateline/2015/4/01/how-severe-is-the-shortage-of-substanceabuse-specialists Accessed July 11, 2020.

11. Turner J: Opportunity Cost and ROI of Fellowships. The White Coat Investor. May 9, 2018. Available at: https://www. whitecoatinvestor.com/opportunity-cost-roi-fellowships/ Accessed July 11, 2020. 